\title{
Assessing Storm Response of Multiple Intertidal Bars Using an Open-Source Automatic Processing Toolbox
}

\author{
Anne-Lise Montreuil ${ }^{1, *(\mathbb{C})}$, Robrecht Moelans ${ }^{2}{ }^{\mathbb{D}}$, Rik Houthuys ${ }^{3}$, Patrick Bogaert ${ }^{4}$ and Margaret Chen ${ }^{1}$ \\ 1 Hydrology and Hydraulic Engineering, Vrije Universiteit Brussel, 1050 Brussels, Belgium; \\ margaret.chen@vub.be \\ 2 Remote Sensing Unit, VITO, 2040 Mol, Belgium; robrecht.moelans@vito.be \\ 3 Geoconsultant, 1502 Halle, Belgium; rik.houthuys@telenet.be \\ 4 Earth \& Life Institute, Université Catholique de Louvain, Louvain-la-Neuve, 1348 Wallonia, Belgium; \\ patrick.bogaer@@uclouvain.be \\ * Correspondence: anne-lise.montreuil@vub.be
}

Citation: Montreuil, A.-L.; Moelans, R.; Houthuys, R.; Bogaert, P.; Chen, M. Assessing Storm Response of Multiple Intertidal Bars Using an Open-Source Automatic Processing Toolbox. Remote Sens. 2022, 14, 1005. https://doi.org/10.3390/rs14041005

Academic Editors: Bas van Wesemael, Trissevgeni Stavrakou, Jean-Christophe Schyns, Joost Vandenabeele, Hans Lievens, Dimitry van der Zande and Kim Calders

Received: 13 January 2022

Accepted: 15 February 2022

Published: 18 February 2022

Publisher's Note: MDPI stays neutral with regard to jurisdictional claims in published maps and institutional affiliations.

Copyright: (c) 2022 by the authors. Licensee MDPI, Basel, Switzerland. This article is an open access article distributed under the terms and conditions of the Creative Commons Attribution (CC BY) license (https:// creativecommons.org/licenses/by/ $4.0 /)$.

\begin{abstract}
Intertidal bars are common features of sandy beaches in meso- and macro-tidal environments, yet their behaviour under storm impact and subsequent recovery remain poorly documented. Intensive surveys provide valuable information; however, it takes time to process the vast amount of data. This study presents the morphological response of a multibarred macro-tidal beach along the Belgian coast after a severe storm that happened on 8-12 February 2020, and to develop and apply an oPen-source Raster prOcessing Toolbox for invEstigation Coast intertidal bar displacemenT (PROTECT) in Python for automated bar extraction. This toolbox was applied to the digital surface models of pre- and post-storm airborne LiDAR surveys of a multibarred intertidal beach. The PROTECT toolbox is capable of detecting the position and elevation of intertidal bars accurately. The uncertainty in the elevation characteristics of the bars induces an error in the elevation dimension of $0.10 \mathrm{~m}$. Using the toolbox, the results showed that the intertidal bars changed in term of variations in bar number, dimensions and shape across the storm event. Overall, the storm significantly eroded the dune and the upper-beach zone with a sand loss equivalent elevation decrease of $-0.14 \mathrm{~m}$. This was followed by a continuous and full recovery after 9 months under fair weather conditions. In contrast, the sand budget in the intertidal zone did not change over the entire monitoring period although the bars showed significant morphological change. Applying the PROTECT toolbox on high-resolution 3D topographic datasets allows to increase the temporal mapping resolution of intertidal bars from long-term (years) to short (storm events) time scales. Similar assessments at locations worldwide would allow the improvement of our knowledge on the morphodynamical role of multibarred beaches and to forecast their evolution, thus contributing to manage future storm response and the progressively accelerating sea level rise.
\end{abstract}

Keywords: automatic bar detection; LiDAR survey; beach morphology; storm; macro-tidal environment

\section{Introduction}

Multiple intertidal bar systems comprise include shore-parallel morphological features characterised by sandy bar crests-troughs. They are commonly present in low to moderate energy coastal environments (i.e., exposed to fetch-limited waves) characterized by a surplus of sand and tidal ranges larger than about $3 \mathrm{~m}$ [1]. The multiple intertidal bar systems are well-developed around semi-enclosed epicontinental seas such as the eastern English Channel, the Irish Sea and the North Sea (e.g., [2-5]). Bars are permanent or to semi-permanent features, $<1 \mathrm{~m}$ high and attaining covering up to lengths of up to several kilometres. They play an important role in protecting the subaerial beach from storm erosion by being a natural buffer and sediment storage. The genesis and morphodynamics (i.e., development, configuration and migration) of bars are affected by external forcing 
factors such as energetic waves with and water level modulations over a broad range of time and space scales [6]. Intertidal beach morphologies are still poorly studied so that our understanding remains limited [1]. Better insights of the dynamics of intertidal bars, and in particular their behaviour under storm impact and subsequent recovery is beneficial for coastal managers and engineers since the evolution of such morphological features is key in governing controlling beach levels elevation as well as in understanding sediment transport across the beach zone.

Ref. [7] have emphasized the importance of considering intertidal bar systems as three-dimensional (3D) morphologies to characterize and analyze their behaviour. The investigation of the 3D bar-trough dynamics and evolution is a challenge due to the logistics of acquiring repeated high-resolution measurements over large spatial $(>1 \mathrm{~km})$ and temporal scales (from weeks to years). Most studies have focused on a single beach profile per survey or at most, a few of such profiles spaced over distances in the order of 0.5 to $1 \mathrm{~km}$, which are commonly repeated several times over a limited time period (e.g., a year) [2]. These do not allow the detection of the spatio-temporal 3D behaviour of a bartrough system. Thus, understanding beach morphology requires collecting datasets to monitor its natural change in a suitable temporal and spatial resolution which is challenging, especially when it is intended to assess bar behaviour in relation to a storm occurrence. Nowadays, high-resolution airborne LiDAR (Light Detecting and Ranging), an active remote sensing system, represents one of the most effective and successful technologies to monitor large beach areas with an accuracy of 5-10 cm [8]. The application of LiDAR data is thus well suited to study small scale features such as sand bars due to their high accuracy and the larger spatial coverage and continuity in repeated LiDAR surveys. LiDAR surveys were acquired over the Belgian coast in the past with a large spatial scale that enable the detection of intertidal bars [9], but not with a suitable temporal resolution for resolving the dynamics of these features in response to storm events, conversely to the present study.

Multiple intertidal bars are ubiquitous along the Belgian coast. The combination of spring high water level and energetic waves can lead there to the occurrence of severe storm such as Ciara event on 8-12 February 2020 that caused widespread beach erosion in the area. Pre- and immediately post-storm LiDAR surveys, extended by surveys up to 9 months after the event were carried out thus offering an exceptional dataset. Traditional analyses of bar system behaviour have been mainly based on extracting a limited amount of cross-shore profiles which may not capture its complete picture or lead to misinterpretation [10]. There is thus the need of suitable tools to automate the detection and extraction of intertidal bars from multiple high-resolution surveys. This research aims to investigate storm impact and recovery of multiple intertidal bars, and to apply the newly developed automatic bar detection algorithm PROTECT toolbox.

\section{Study Site}

The Belgian coast extends for $67 \mathrm{~km}$ from the French Opal coast to the border with the Netherlands and is oriented SW-NE (Figure 1). The study site is located at Groenendijk, a natural sandy beach, $500 \mathrm{~m}$ wide, with an overall slope of less than $1 \%$ and characterized by multiple parallel bars in the intertidal zone. A system of four to five bars is present from which the first bar is usually located seaward of the first troughs. The shoreface also displays a subtidal bar. Bar dimensions are typically around $1.1 \mathrm{~m}$ high and $82 \mathrm{~m}$ wide [5]. Cross-shore drainage channels segment the bar-trough system. The sediment on the beach consists of medium fine sand with a D50 of $200 \mu \mathrm{m}$. The intertidal bars are backed by an upper-beach of about $50 \mathrm{~m}$ wide following by well-developed foredunes that reach to $10 \mathrm{~m}$ high above TAW (Belgium Ordnance Datum corresponding to the low spring tide located just below $0 \mathrm{~m}$ TAW in Ostend) and are relatively well covered by marram grasses. The annual gain in sediment volume is about $21 \mathrm{~m}^{3} / \mathrm{m}$ over the last decades [11]. The study site is characterized by a macro-tidal, semi-diurnal tidal regime with a small symmetry. The mean tidal range varies from $3.5 \mathrm{~m}$ during neap to $5 \mathrm{~m}$ during spring tide resulting in strong alongshore tidal currents reaching about $1 \mathrm{~m} / \mathrm{s}$ in the nearshore area [12]. The shallow 
subtidal zone of this region is characterized by numerous sandbanks and channels. The wave regime is characterized by an onshore average wave height below $1 \mathrm{~m}$ and a mean wave period of 3.5-4.5 s. Waves are typically short-crested mainly due to the short fetch and the shallow water depth. Storms are recorded at least once a year during the winter season and may cause beach erosion [13]. This occurred also during the 8-12 February 2020 Ciara storm surge when the water level exceeded $5.78 \mathrm{~m}$ TAW associated with energetic waves coming from NW.
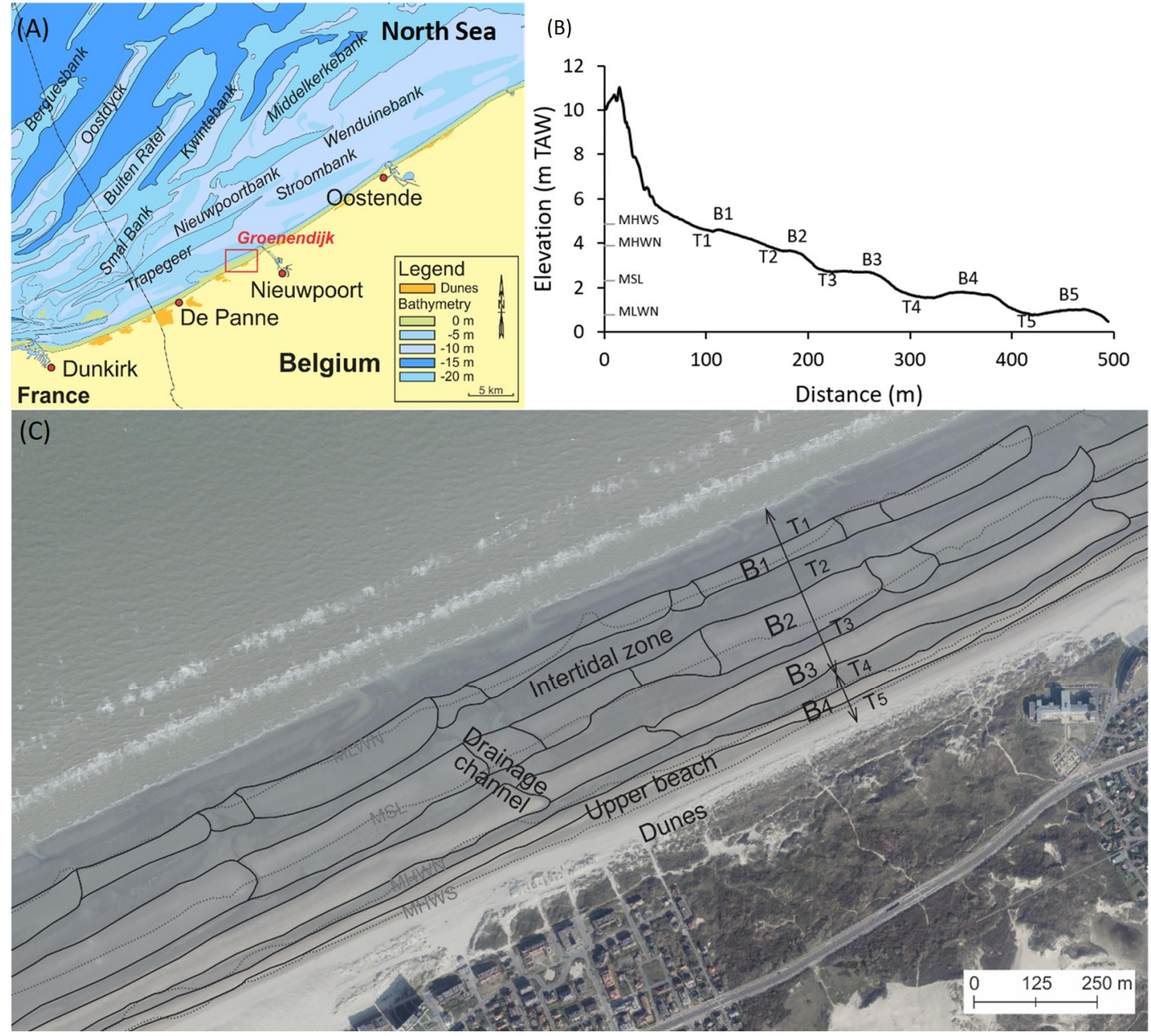

Figure 1. (A) Location map of Groenendijk beach, (B) typical beach profile and (C) schematic multiple bar (B) trough (T) morphology system superimposed on an aerial photograph. The tide contour levels are: mean high water spring (MHWS) of $4.84 \mathrm{~m}$; mean high water neap (MHWN) of $3.88 \mathrm{~m}$; mean sea level (MSL) of $2.31 \mathrm{~m}$; mean low water neap (MLWN) of $0.77 \mathrm{~m}$.

\section{Materials and Methods}

\subsection{LiDAR Dataset Collection and Processing}

Pre-storm (29 October 2019), immediately after storm (28 February 2020), 2 months after (14 April 2020) and 9 months after (18 November 2020) airborne LiDAR surveys were commissioned by the Coastal Division of the Flemish Authorities. The datasets consist of $3 \mathrm{D}$ point clouds $(x, y, z)$ with a cover density of 1 to 5 points per $\mathrm{m}^{2}$. For each survey, a smooth Digital Surface Model (DSM) of $1 \mathrm{~m}$ cell size was generated using a 2D Gaussian filter of $10 \mathrm{~m}$ (i.e., standard deviation for Gaussian kernel). In addition, a beach filtering to apply a labelling on the valid data in the DSM was carried out to exclude pixels with no data value. The root-mean-square errors of the generated DSMs range from 0.04 to $0.05 \mathrm{~m}$. For the current analysis, a DSM extent of $2 \mathrm{~km}$ long and up to $0.46 \mathrm{~km}$ wide, was 
used, with a landward limit located up to $20 \mathrm{~m}$ beyond the dunetoe. DEMs of Difference (DoDs) between the DSMs were produced by subtracting the elevation in each grid on a cell-by-cell basis. To further investigate sediment dynamics, the beach was horizontally split into two areas of interest: the upper-beach from the landward edge of the DSM to the MHWS line; and the intertidal zone from the MHWS to the seaward edge of the DSM. The sediment budget of areas of interest was calculated from the DoDs and classified into erosion, stability, deposition. Volumetric changes per unit surface per time were then computed, enabling comparison of volumetric results despite differences in the duration between surveys.

\subsection{Bar Detection Procedure}

The detection of bar location was automated by developing the PROTECT toolbox, an algorithm written in the Python programming language and made available through open-source access (https:/ / zenodo.org/record/5750179\#.Yaj-LbnMKUk (accessed on 16 February 2022)) [14]. Figure 2 presents the workflow from LiDAR data processing to bar analysis. A series of cross-shore profiles from the low water line to the dune crest is extracted from the DSMs, with alongshore distances of $2 \mathrm{~m}$ between subsequent profiles. The intertidal bar feature points (crest and trough positions of the bars) are determined from the cross-shore profiles by detecting each inflection point (i.e., transition between crest and trough, defined a position along the profile where the curve change from being concave to convex, or vice versa) along the beach slope. Then, the crest points (local maxima) and trough points (local minima) could be extracted (Figure 3). Two strict conditions are further applied to avoid tagging irrelevant points. First, elevation of the crest point must be higher compared to the trough point for the same intertidal bar. Second, the absolute distance between the crest and trough points within the same inflection interval has to be above a user-specified threshold between 3 to $5 \mathrm{~m}$. A neighbourhood filtering on the intertidal bar feature points is then used to remove isolated crest, trough or inflection points related to drainage channels or local variations in topography which unrepresented intertidal bars. A filter window of $20 \mathrm{~m}$ by $10 \mathrm{~m}$ is applied parallel to the coastline orientation. Based on the locations of the intertidal bar features points (i.e., crest and trough), bar parameters are subsequently derived such as bar elevation, width, height, symmetry and volume (Table 1).

To delineate the actual intertidal bars, a grouping of the bar feature points is performed using an unsupervised machine learning technique, i.e., density-based spatial clustering of applications with noise (DBSCAN), available in scikit-learn. The algorithm views clusters as areas of high feature point density separated by areas of low density. Feature points of intertidal bars (crest, trough or inflection points) are in general well aligned with the coastline and beach topography clearly increases towards the dunes. Detected bars are then imported into a geographic information system (ESRI ArcGIS) to be visualized and assessed by overlapping on their respective DSM. A numbering system is applied to crest points to identify the bar structure to which they belong (Figures 1 and 3).

Table 1. Definition of parameters to characterize bar morphology.

\begin{tabular}{cr}
\hline Parameter & Description \\
\hline Bar elevation $(\mathrm{m} \mathrm{TAW})$ & Height value at the position of the crest point \\
\hline Bar width $(\mathrm{m})$ & Distance between two consecutive troughs related to a bar \\
\hline Bar height $(\mathrm{m})$ & Difference of elevation between the crest and seaward trough point \\
\hline $\begin{array}{c}\text { Bar symmetry } \\
\text { dimensionless })\end{array}$ & $\begin{array}{c}\text { Horizontal distance between the crest and landward trough point, } \\
\text { divided by the horizontal distance between the trough points on both } \\
\text { sides of the bar. }\end{array}$ \\
\hline Bar volume $\left(\mathrm{m}^{3} / \mathrm{m}\right)$ & $\begin{array}{c}\text { Area below the profile curve between the landward trough and } \\
\text { seaward trough minus the area under the linear curve when } \\
\text { connecting the seaward and landward trough points. }\end{array}$
\end{tabular}




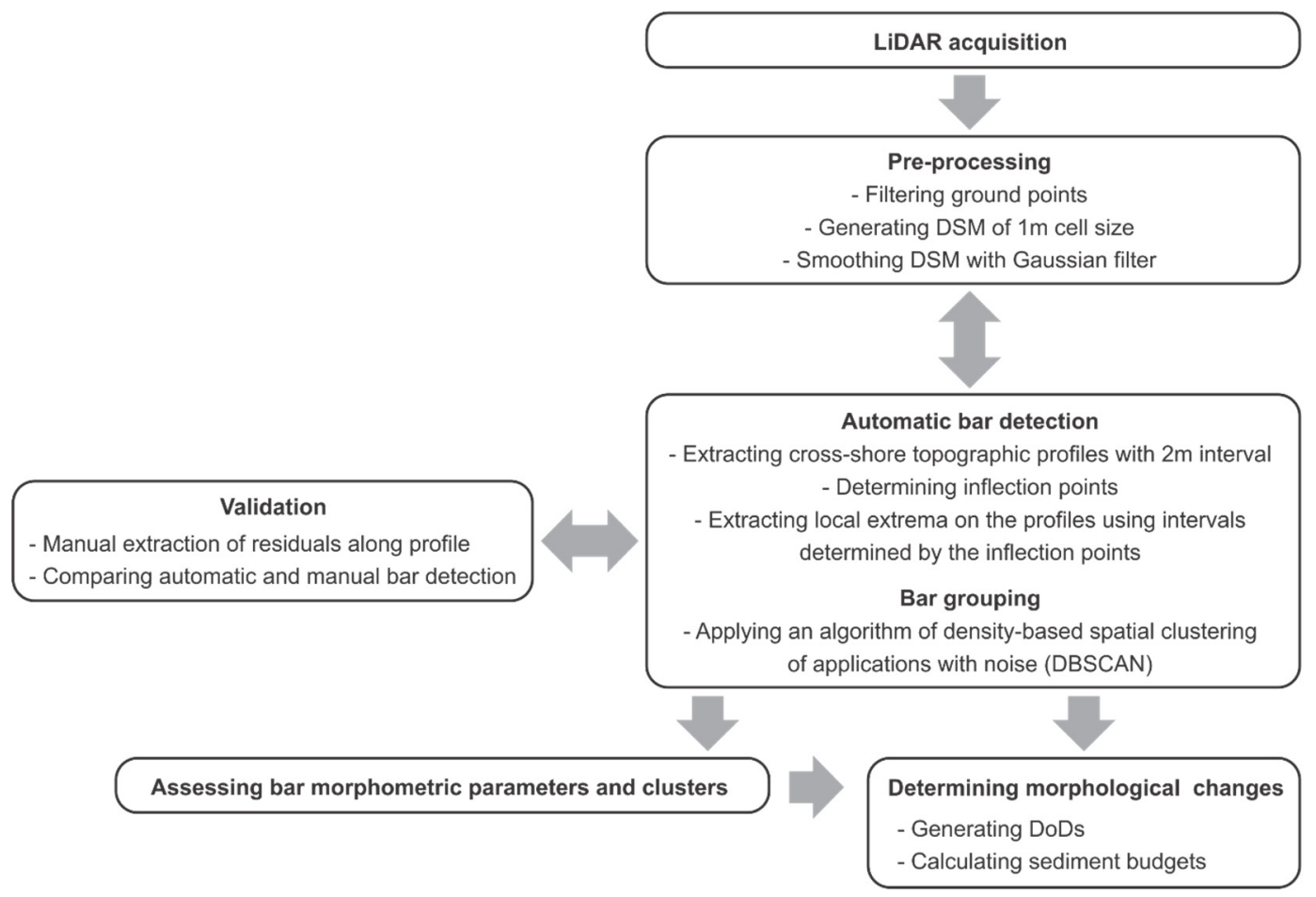

Figure 2. Workflow of PROTECT toolbox and analyses.

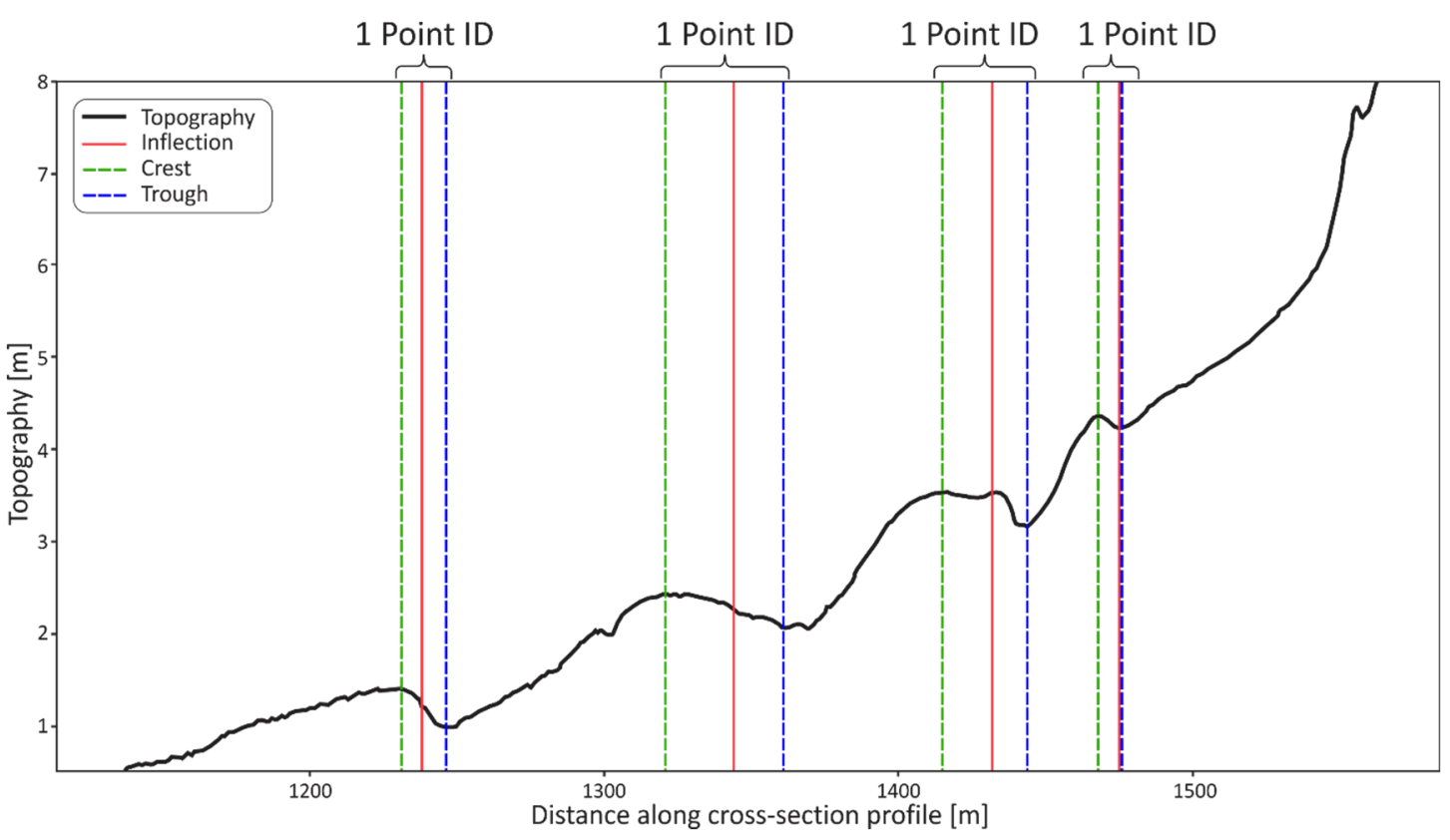

Figure 3. Example of inflection points (red), crest points (green) and trough points (blue) along a cross-shore profile extracted from the LiDAR dataset (Moelans et al., 2021 modified).

To evaluate the performance of the algorithm, the bar extraction result was validated by comparing with a manual extraction of every survey along 6 profiles homogenously distributed with an interval of $200 \mathrm{~m}$. The six profiles were extracted from the DSMs. Then a second-order polynomial curve was fitted to the profiles using least-squares analysis in order to determine the maxima and minima residual values, following [2]. In total, 102 bar position were detected. In general, the difference between the automatic and manual extraction is low with an average of $0.09 \mathrm{~m}$ for the bar elevation and $4 \mathrm{~m}$ for the bar position (Figure 4). The results also suggest that the algorithm slightly overestimates the elevation of 
the bar. A high coefficient of determination $\left(\mathrm{R}^{2}\right)$ is found for the bar elevation and position are of 0.96 and 0.99 , respectively. Therefore, the algorithm is capable to identify accurately the bar crests across the intertidal beach.

(A)

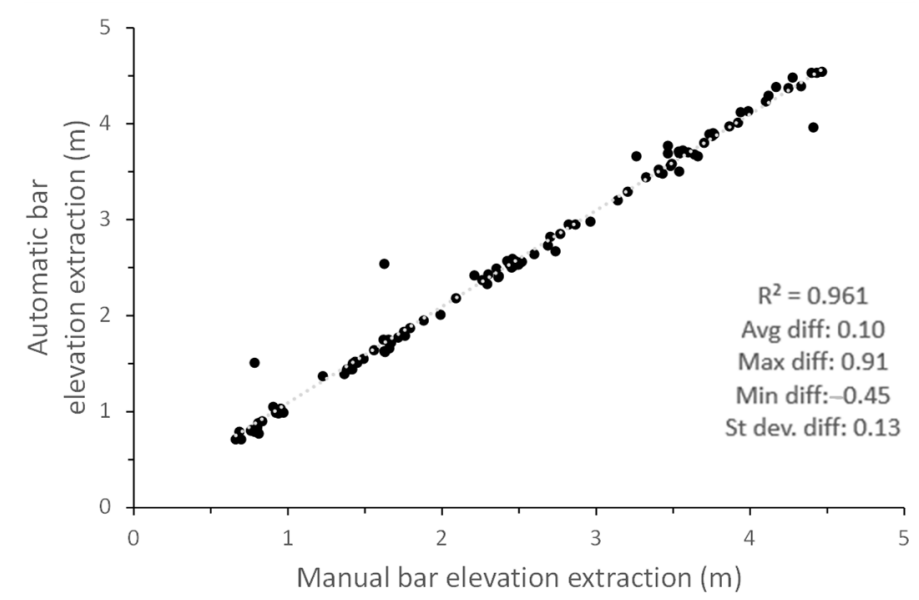

(B)

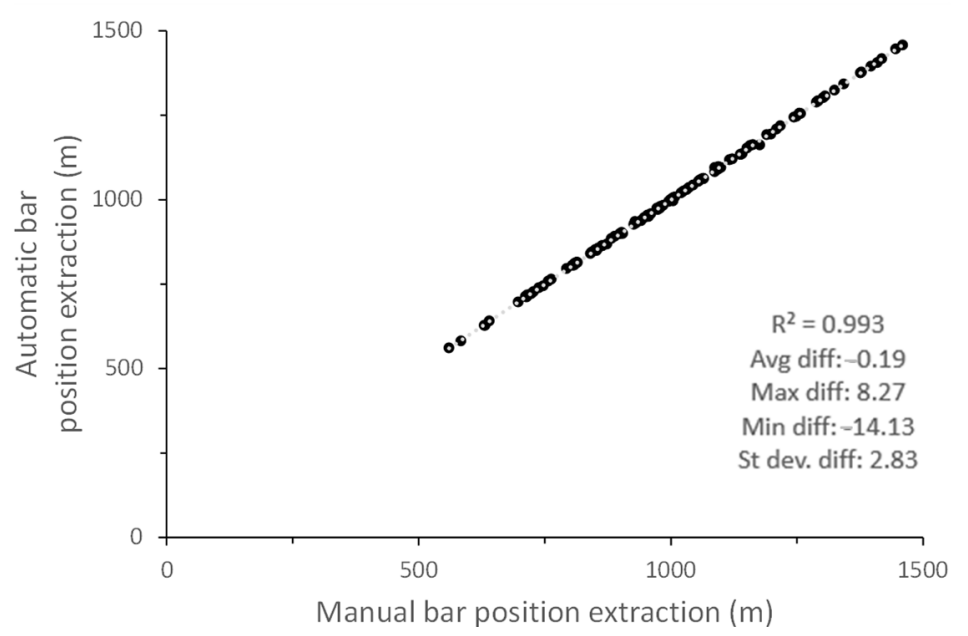

Figure 4. Comparison between automatic and manual extraction for (A) position and (B) elevation of bars (number of bar crest: 102).

\section{Results}

\subsection{Storm Activity}

Water level and significant wave height (Hs) were examined to determine the conditions of the forcing factors over the entire monitoring period. Five-minute measurements of the water level were obtained from the nearest tide gauge located at Nieuwpoort, $2 \mathrm{~km}$ distance from the study site (Figure 1A). Bi-hourly onshore wave heights were recorded at Trapegeer wave buoy, located at $6 \mathrm{~km}$ from the study site. Measurements of wind speed and direction with an interval of 10-min were acquired from the weather station at Nieuwpoort. All these data were supplied by Meetnet Vlaamse Banken (https:/ / meetnetvlaamsebanken.be/ (accessed on 20 November 2021)).

Five energetic events with a water level exceeding $5.4 \mathrm{~m}$ TAW for an average duration of $1.53 \mathrm{~h}$ took place between 29 October 2019-28 February 2020 (Table 2). The maximum water level reached $5.86 \mathrm{~m}$ TAW on 10/02 at 12:30 when the waves reached $3.15 \mathrm{~m}$ high associated with a strong wind coming from the North. The alert threshold of a 'dangerous storm' of $5.60 \mathrm{~m}$ TAW was exceeded by a surge of $0.26 \mathrm{~m}$. Right after the storm, the wave heights rapidly decreased to reach typical fair-weather conditions below $1 \mathrm{~m}$. Three and two events occurred between 28 February 2020-10 April 2020 and 10 April 2020-18 
November 2020, respectively. The average wave height was lower associated with relatively calm wind speed during the post-storm periods. Although the maximum Hs exceeded $2 \mathrm{~m}$ during the post-storm periods, these events were short-lived $(<1.75 \mathrm{~h})$ associated with neither coast-normal wave directions nor surges. Thus, relatively calm conditions generally prevailed after the storm event.

Table 2. Summary of hydrodynamic conditions over the monitoring period. Energetic event is characterized by a water level above $5.4 \mathrm{~m}$ TAW.

\begin{tabular}{ccccc}
\hline & & $\begin{array}{c}\text { 29 October } \\
\text { 2019-28 February }\end{array}$ & $\begin{array}{c}\text { 28 February } \\
\mathbf{2 0 2 0 - 1 0 ~ A p r i l ~} \\
\text { 2020 }\end{array}$ & $\begin{array}{c}\text { 10 April 2020-18 } \\
\text { November 2020 }\end{array}$ \\
\hline & Number energetic event & 5 & 3 & 2 \\
Forcing factors & Duration & $1.53[2.6]$ & $1.44[1.58]$ & $1.62[1.75]$ \\
& Water level (m) & $5.56[5.86]$ & $5.52[5.68]$ & $5.51[5.56]$ \\
& Significant wave height $(\mathrm{m})$ & $2.44[3.15]$ & $1.71[2.09]$ & $1.77[1.99]$ \\
& Wind direction $\left({ }^{\circ}\right)$ & $265[277]$ & $72[126]$ & $268[272]$ \\
& Wind speed $(\mathrm{m} / \mathrm{s})$ & $17.2[20.2]$ & $3.89[4.96]$ & $11.74[13.74]$ \\
\hline
\end{tabular}

\subsection{Bar Detection, Mapping and Characteristics}

Figure 5 shows the automatically detected bar positions across the study area obtained from the LiDAR surveys and superimposed on their respective DSMs. The bars are numbered from the sea to the dune. The black contour lines correspond to the tidal reference levels of mean high water springs (MHWS) of $4.84 \mathrm{~m}$; mean high water neaps (MHWN) of $3.88 \mathrm{~m}$, mean sea level (MSL) of $2.31 \mathrm{~m}$, and mean low water neap (MLWN) of $0.77 \mathrm{~m}$. The bars are prominent on the intertidal beach and their number typically ranges from four to five in cross-shore dimension. The subtidal bar at $-2 \mathrm{~m}$ TAW cannot be observed in the LiDAR dataset. Bars are usually parallel to the coastline and are distributed fairly evenly across the beach. The bars are present across the intertidal zone and concentrated between the MHWN and MLWN lines. Inner bars above the MHWN line (bar number 4-5) are less commonly observed. The individual bars can be extended well over large alongshore distances $(>500 \mathrm{~m})$ and be either continuous or laterally fragmented due to the presence of modest drainage channels.

The identified bars present different trends on large-scale bar configuration change over the storm monitoring period. The first is that five bars across the intertidal beach were present before and 9 months after the storm, while only four bars were identified immediately and 2 months after the event. Noteworthy, these features were continuous in the alongshore direction over the post-storm monitoring period, while on 29 October 2019 they were intersected by frequent drainage channels and/or local beach topographic ruptures.

Figure 6 presents the cluster plots of all the extracted bar crests along the cross-shore profiles generated by the toolbox. The $y$-axis corresponds to the beach elevation and the $x$ axis to the distance from the reference line located seaward. Another common pattern after the storm is that the bars occupied a number of preferential elevational positions across the intertidal beach: inner bar (number 4) between 3.5-3.7 m TAW, middle bar (number 3) around the MSL line, and the lower bar (number 2) around $1.6 \mathrm{~m}$ TAW. However, the preferential positions were different before the storm located in average $0.3 \mathrm{~m}$ higher than the post-storm positions. In addition, they had a more spread out configuration as shown on the cluster plot. The position of the bar system is dynamic and complex between consecutive surveys, exhibiting a large spatial and temporal variability. Although the detected bar morphology displays some similarity, it is only with difficulty that the development of some individual bars can be tracked between consecutive surveys due to their temporal spacing. This thus precludes the following of individual bars to investigate their migration rate and direction. It can at this stage not be concluded whether bars migrated seawards or were flattened and rebuilt during the storm event. 


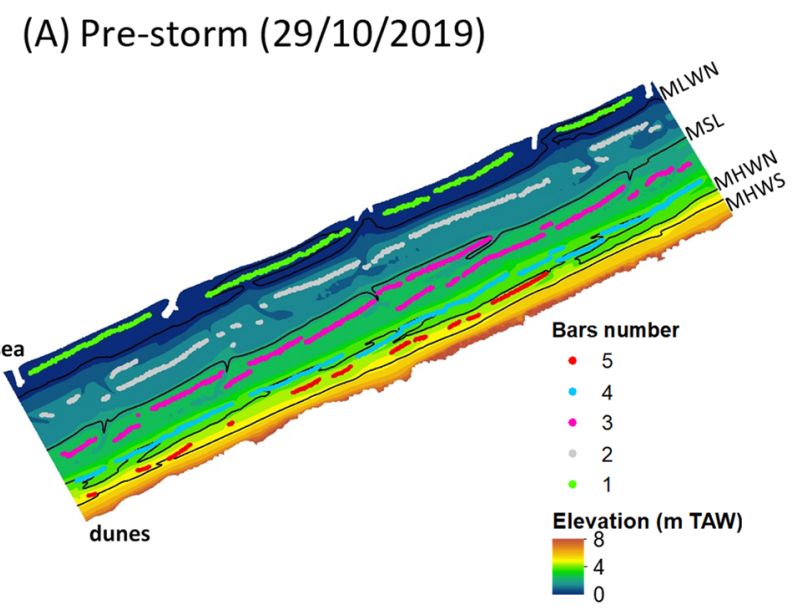

(B) Immediately after storm (28/02/2020)

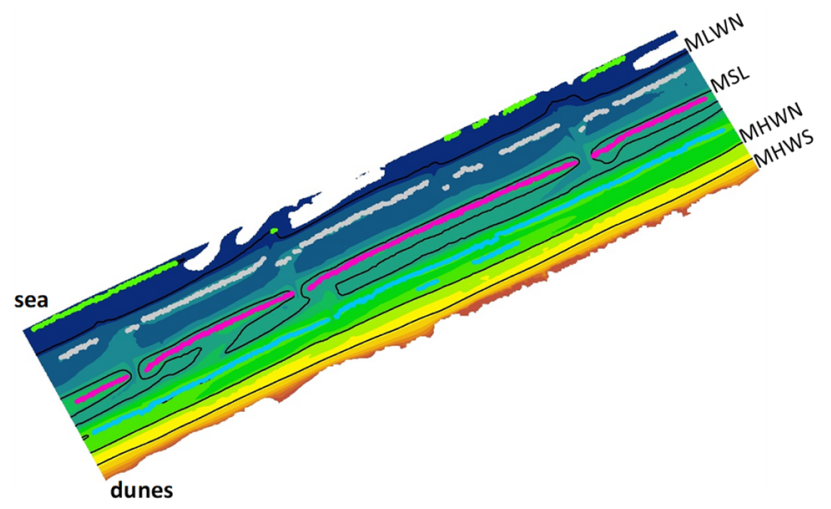

(C) 2 months after storm (14/04/2020)

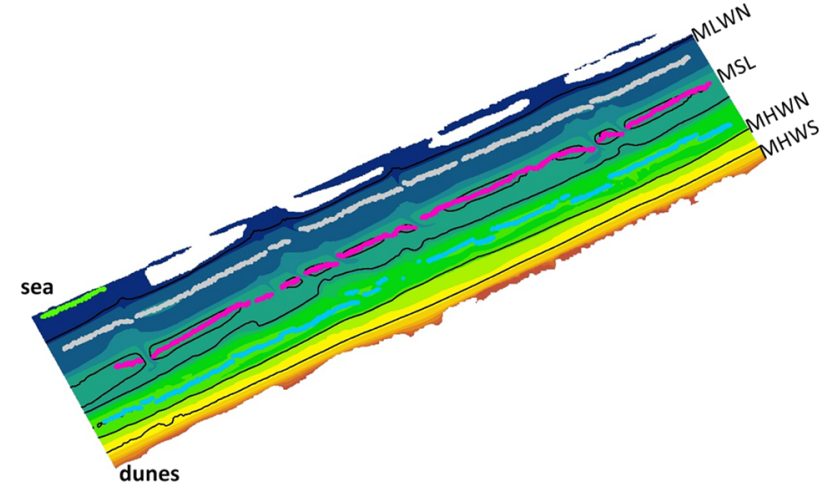

(D) 9 months after storm $(18 / 11 / 202)$

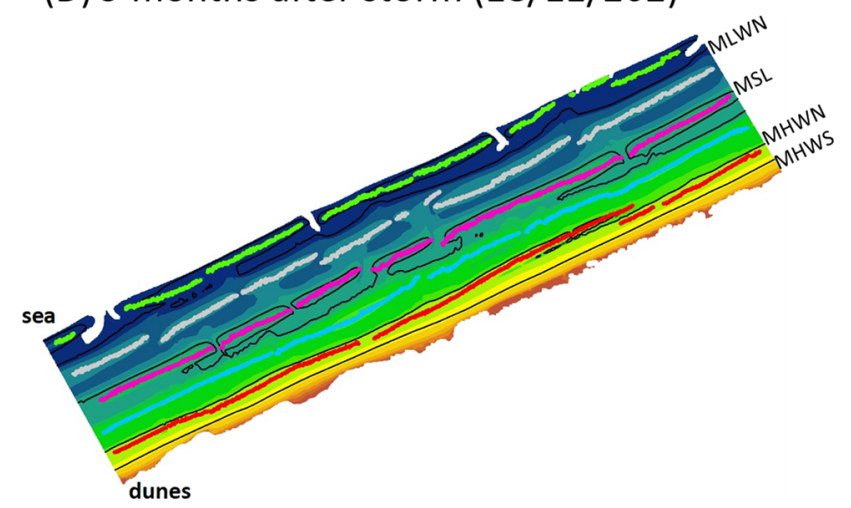

Figure 5. Maps of the automatically detected bars (thick coloured lines) superimposed on their respective DSMs at (A) pre-storm (29 October 2019), (B) immediately after storm (28 February 2020), (C) 2 months after (14 April 2020) and (D) 9 months after (18 November 2020). 
(A) Pre-storm (29/10/2019)

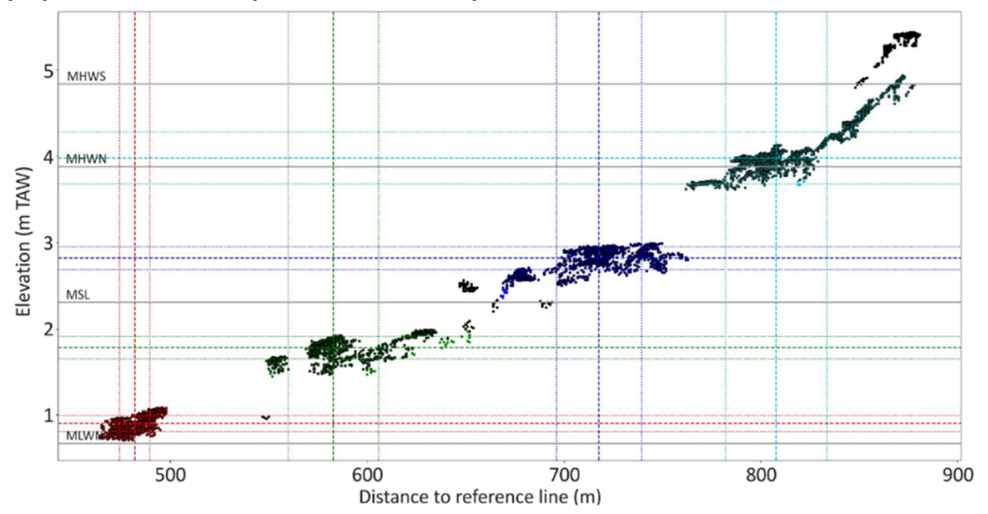

(B) Immediately after storm (28/02/2020)

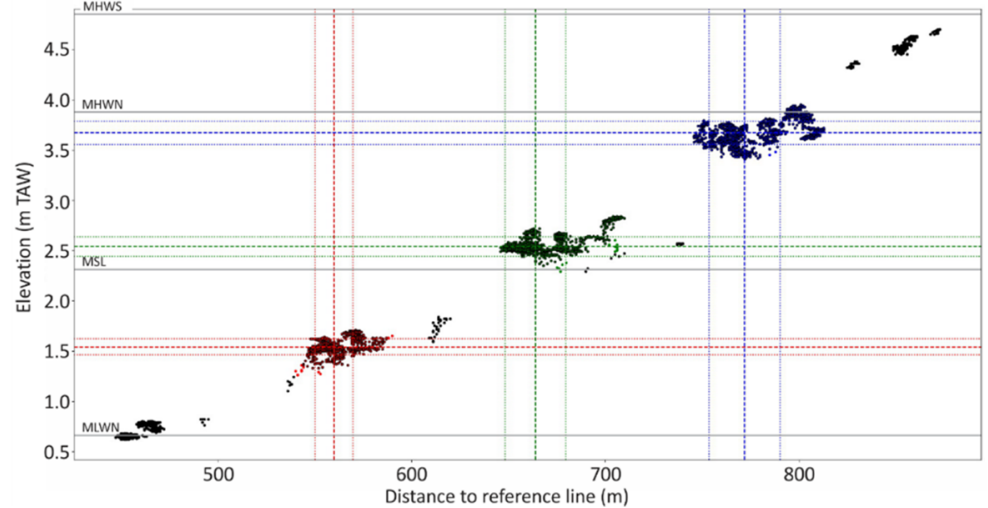

(C) 2 months after storm (14/04/2020)

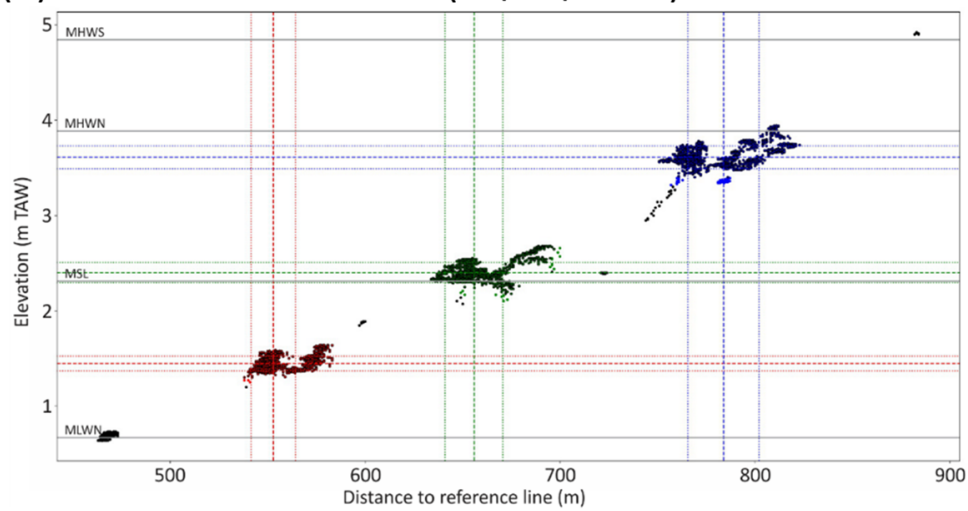

(D) 9 months after storm (18/11/2020)

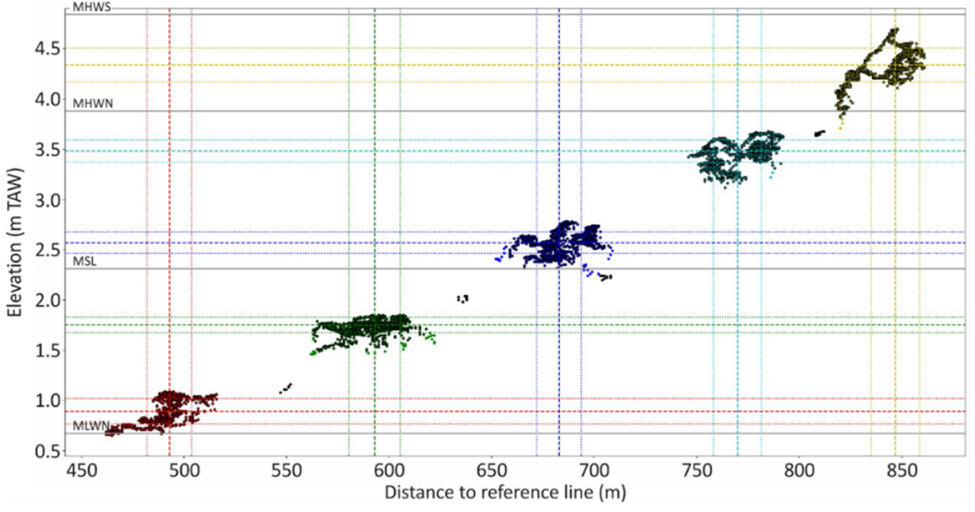

Figure 6. Cluster plots over all cross-profiles of bar elevation on (A) 29 October 2019 (pre-storm), (B) 28 February 2020 (immediately after storm), and (C) 14 April 2020 (2 months after) and (D) 18 November 2020 (9 months after). Note: The axes are different due to the slight size difference of the DSM. 
The bar system characterisation is detailed in Table 3. A clear spatial variability in the bar parameters across the intertidal beach is observed. Regarding the whole monitoring period, the bars are characterized by a mean height above $1.1 \mathrm{~m}$ with the highest ones generally found on the upper-part of the intertidal beach ( $>=$ bar 4$)$. The widest bars are located in the middle part of the intertidal zone between MLWN and just above the MSL (bar 3 and 2) followed by the ones on the upper-part of the intertidal beach. The same pattern is found for the bar volume, ranging from 9 to $36 \mathrm{~m}^{3} / \mathrm{m}$. In general, the bar shape is asymmetric with a trend to skew towards the land, so that the landward slope is steeper than the seaward slope, compared with the more seaward bars. Just after the storm, the volume of the seaward features (Bar 1 and Bar 2) was lower associated with a decrease of width and height. In contrast, the upper bars were larger and higher with a steeper landward slope.

Table 3. Summary of averaged bar parameters across the profiles for pre- and post-storm surveys.

\begin{tabular}{|c|c|c|c|c|c|c|}
\hline & & $\begin{array}{l}\text { Elevation } \\
\text { (m TAW) }\end{array}$ & $\begin{array}{l}\text { Width } \\
\text { (m) }\end{array}$ & $\begin{array}{c}\text { Symmetry } \\
\text { (Dimensionless) }\end{array}$ & $\begin{array}{l}\text { Volume } \\
\left(\mathrm{m}^{3} / \mathrm{m}\right)\end{array}$ & $\begin{array}{l}\text { Height } \\
\text { (m) }\end{array}$ \\
\hline \multirow{5}{*}{$\begin{array}{l}29 \text { October } \\
2019\end{array}$} & Bar 1 (sea) & 0.90 & 90 & 0.30 & 20 & 0.95 \\
\hline & Bar 2 & 1.77 & 92 & 0.30 & 22 & 1.02 \\
\hline & Bar 3 & 2.79 & 90 & 0.25 & 21 & 1.08 \\
\hline & Bar 4 & 4.06 & 57 & 0.22 & 10 & 1.18 \\
\hline & Bar 5 (land) & 4.42 & 52 & 0.21 & 9 & 1.05 \\
\hline \multirow{5}{*}{$\begin{array}{c}28 \text { February } \\
2020\end{array}$} & Bar 1 (sea) & 0.72 & 37 & 0.30 & 15 & 0.16 \\
\hline & Bar 2 & 1.57 & 58 & 0.30 & 18 & 0.61 \\
\hline & Bar 3 & 2.57 & 109 & 0.38 & 36 & 1.25 \\
\hline & Bar 4 & 3.67 & 76 & 0.31 & 22 & 1.46 \\
\hline & Bar 5 (land) & & & & & \\
\hline \multirow{5}{*}{10 April 2020} & Bar 1 (sea) & 0.69 & 35 & 0.28 & 15 & 0.16 \\
\hline & Bar 2 & 1.46 & 88 & 0.28 & 16 & 0.94 \\
\hline & Bar 3 & 2.42 & 101 & 0.31 & 25 & 1.10 \\
\hline & Bar 4 & 3.62 & 96 & 0.23 & 20 & 1.47 \\
\hline & Bar 5 (land) & & & & & \\
\hline \multirow{5}{*}{$\begin{array}{c}18 \\
\text { November } \\
2020\end{array}$} & Bar 1 (sea) & 0.90 & 90 & 0.29 & 20 & 0.98 \\
\hline & Bar 2 & 1.73 & 85 & 0.29 & 24 & 1.07 \\
\hline & Bar 3 & 2.57 & 85 & 0.30 & 26 & 1.22 \\
\hline & Bar 4 & 3.46 & 73 & 0.29 & 17 & 1.25 \\
\hline & Bar 5 (land) & 4.33 & 55 & 0.18 & 7 & 1.16 \\
\hline
\end{tabular}

\subsection{Barred Beach Morphodynamics}

The spatial patterns of morphological changes are displayed in the DoDs, with green showing deposition and red erosion (Figure 7). The immediate topographic change induced by the storm is observed on the DoD between the pre- and immediately after the event surveys (29 October 2019-28 February 2020). A significant sand loss of $-12,214 \mathrm{~m}^{3}$ was recorded in the upper-beach where the dune was undercut after the storm (i.e., uncertainty of $4400 \mathrm{~m}^{3}$ ). A long and continuous strip line of erosion is visible landward of the MHWS line with higher values of elevation change up to $-0.6 \mathrm{~m}$. The mean elevation change in the intertidal zone was $-0.01 \mathrm{~m}$. 
(A) Pre - immediately after storm (29/10/2019-28/02/2020)

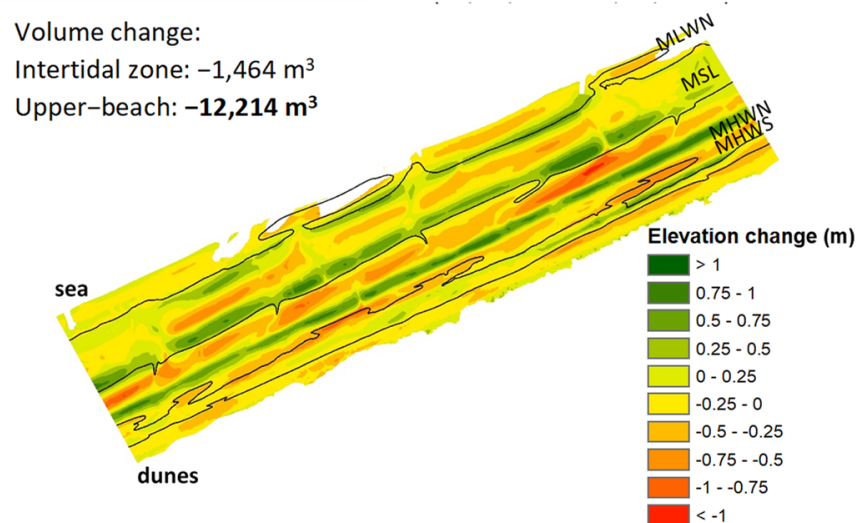

(B) Immediately - 2 months after storm (28/02/2020 - 10/04/2020)

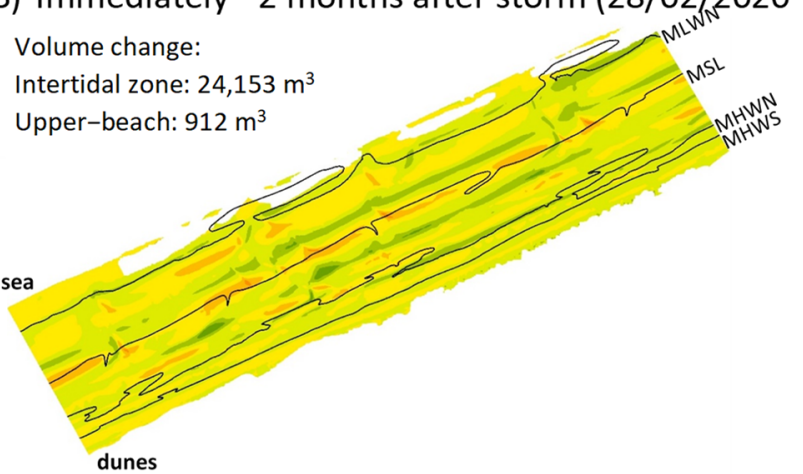

(C) 2 months later - 9 months after storm (10/04/2020 - 18/11/2020)

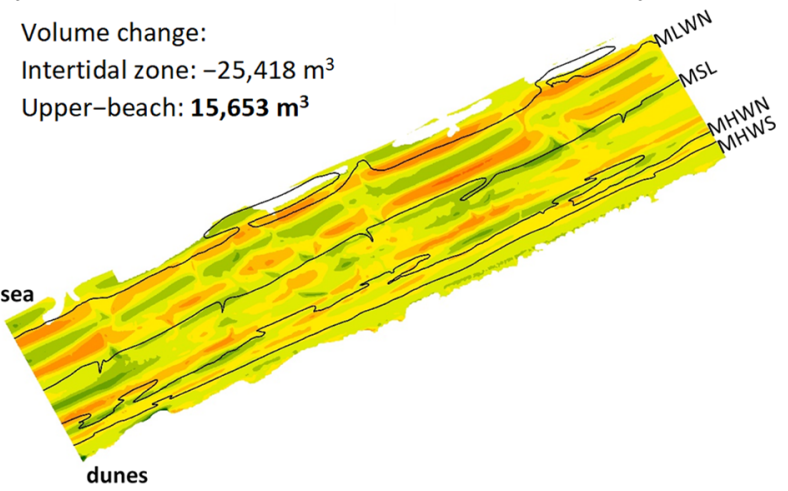

(D) Pre - 9 months after storm (29/10/2019 - 18/11/2020)

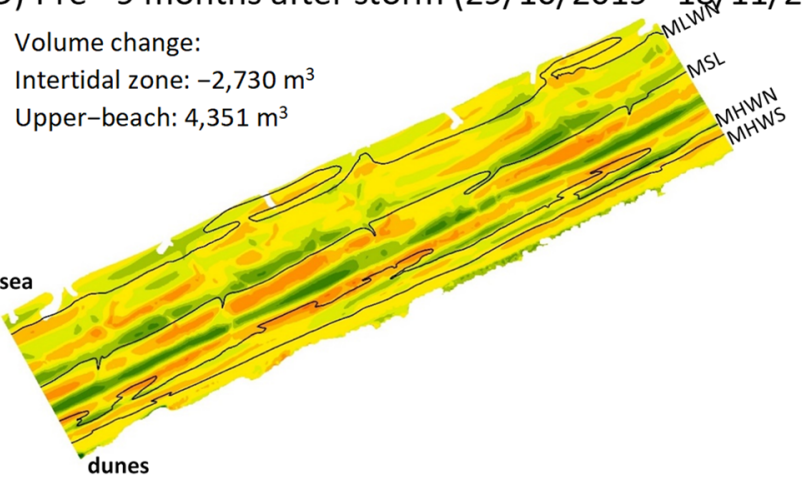

Figure 7. DoDs of pre- and post-storm surveys: (A) pre-storm-immediately later storm, (B) immediately -2 months later storm, (C) immediately -9 months later storm, (D) pre-storm-9 months later storm. For indication, the tidal reference levels on 29 October 2019 are added in black lines. The uncertainty errors on the intertidal zone and upper-beach per survey are estimated to be $40,150 \mathrm{~m}^{3}$ and $4400 \mathrm{~m}^{3}$, respectively. Both are equivalent to an error on elevation difference of $0.05 \mathrm{~m}$. 
Although the intertidal beach experienced volumetric stability with fluctuations within the survey uncertainty error, a substantial sediment fraction of the intertidal beach was reworked in the bar system, as reflected by the distinctive linear alongshore footprint of alternating erosion and deposition. Erosion reached up to $-1 \mathrm{~m}$ in the northeast of the study site which was counterbalanced alongside by an equal accretion. After the storm, the bars occupied a more seaward position of about $30 \mathrm{~m}$. Over the 2 months after the storm (28 February 2020-10 April 2020), no significant volumetric change occurred on the upper-beach nor in the intertidal zone. However, linear patterns of erosion and deposition again describe the shift in the bars position. The range of elevation change between -0.64 and $0.73 \mathrm{~m}$ is much lower than for the pre-immediate after storm DoD. However, significant morphological changes occurred in the intertidal zone, which is largely attributed to the specific dynamics and processes of the bars. As immediately after the storm, the distinct linear, alternated and relatively symmetrical footprint of erosion and deposition parallel to the coast is observed. The bars remained generally confined between the MHWN and MLWN line, but were locally rearranged with limited displacement. Afterwards between 10 April 2020-18 November 2020, accretion took place in the upper-beach, mainly along the seaward side of the dune. Regarding the intertidal zone, no significant volume change was observed during this period. The DoD indicates a much more important rearrangement of the bars compared to the previous period (28 February 2020-10 April 2020), which can obviously be related to a larger time lapse between the surveys. The DoD between the pre- and 9 months after storm surveys shows that the dynamics of the bars were greater in the upper part of the intertidal zone between the MHWN line and just seaward of the MSL line. In addition, a considerable alongshore variability of the elevation change is observed there, ranging from 0.2 to $0.73 \mathrm{~m}$. A small significant sand deposition occurred on the upper-beach, especially at the dunetoe, while the intertidal zone was stable over this period.

\section{Discussion}

Our analysis applied the PROTECT toolbox, a new open-source raster processing toolbox for automated intertidal bar extraction developed in Python, to a unique dataset of pre- and post-storm LiDAR surveys of a macro-tidal beach environment at Groenendijk. Table 4 summarizes some key values of the hydrodynamics, and the morphodynamic differences of the multibarred beach presented in the results section.

Table 4. Summary of average energetic events exceeding a water level of $5.4 \mathrm{~m}$ TAW related to volumetric changes. Bracket values correspond to the maximum records. Bold values indicate significant change.

\begin{tabular}{|c|c|c|c|c|}
\hline & & $\begin{array}{c}\text { 29 October } \\
2019-28 \text { February } \\
2020\end{array}$ & $\begin{array}{c}28 \text { February } \\
2020-10 \text { April } \\
2020\end{array}$ & $\begin{array}{l}10 \text { April 2020-18 } \\
\text { November } 2020\end{array}$ \\
\hline \multirow{4}{*}{$\begin{array}{l}\text { Volumetric } \\
\text { difference }\end{array}$} & $\begin{array}{l}\text { Absolute volume of the } \\
\text { intertidal zone }\left(\mathrm{m}^{3}\right)\end{array}$ & -1464 & 24,153 & $-25,418$ \\
\hline & $\begin{array}{l}\text { Volume of the } \\
\text { intertidal zone } \\
\left(\mathrm{m}^{3} / \mathrm{month}\right)\end{array}$ & -366 & 16,855 & -3498 \\
\hline & $\begin{array}{l}\text { Absolut volume of the } \\
\text { upper-beach }\left(\mathrm{m}^{3}\right)\end{array}$ & $-12,214$ & 912 & 15,653 \\
\hline & $\begin{array}{l}\text { upper-beach } \\
\left(\mathrm{m}^{3} / \text { month }\right)\end{array}$ & -3054 & 636 & 2154 \\
\hline
\end{tabular}

\subsection{Beach Response and Recovery Periods}

The Ciara storm caused an overall erosion of $-12,214 \mathrm{~m}^{3}$ equivalent to $-3054 \mathrm{~m}^{3} / \mathrm{month}$ with the undercutting of the foredune concentrated in the south of the study site and with an homogeneous erosion of the upper-beach slope (Figure 7, Table 4). The eroded sand of the upper-beach may have been transported partly offshore to the upper part of the shoreface and partly to the adjacent beaches by the eastward littoral drift as previously 
observed there after storm events [15]. The sand budget in the intertidal zone was neutral, however the bars were mobile and showed changes in their characteristics (Table 3). Ref. [5] further observed significant changes in bar dimension and shape with a clear seasonal variability between spring and autumn associated with energetic and calm hydrodynamic conditions, respectively. A continuous and full recovery of the upper-beach was observed after 9 months when sand was deposited there and near the dunetoe. This evolution is probably partly caused by constructive wave transport as they did not reach the upperbeach during fair weather conditions [15]. Sediment was then transported by aeolian processes to the dunes. Additionally, the relatively rapid recovery of the upper-beach suggests that the recovery processes started right after the end of the storm (i.e., abatement of wave energy) when recovery mechanisms may have taken place within weeks after the severe storm event. This is in agreement with previous studies $[15,16]$ who observed fast recovery within a few months or even during the subsiding phase of the same storm [17]. Beach recovery after a storm depends on the available sediment to the system. At the study site, the beach experiences a long-term accretion. This promoted a rapid dissipative beach re-equilibrium.

The most dynamic bars at Groenendijk beach are found across the intertidal zone between the MHWN to the MLWN line. This reflects a propensity for significant bar development in this zone governed by the residence times of wave driven processes at particular tidal elevations [2]. This pattern is fairly common on multibarred beaches, and it is probably favoured at Groenendijk beach by the large sediment supply at the coast $[11,15]$. No energetic event before Ciara storm resulted to significant bar morphological change as shown on the cross-shore profiles extracted from LiDAR surveys and the Real-Time Kinematic GPS (RTK-GPS) survey just before the storm (Figure 8). One of the most significant observations is that the bars migrated seaward during the storm, while they seem to be more stable in position during the two first recovery periods (from 28 February 2020-10 April 2020) and to then move slightly toward the upper-beach. As previously reported, bars migrate offshore during storms and move back under prolonged calm wave conditions [18]. Therefore, hydrodynamic forcing factors influence intertidal bar responses including migration, formation, flattening, construction and destruction [6].

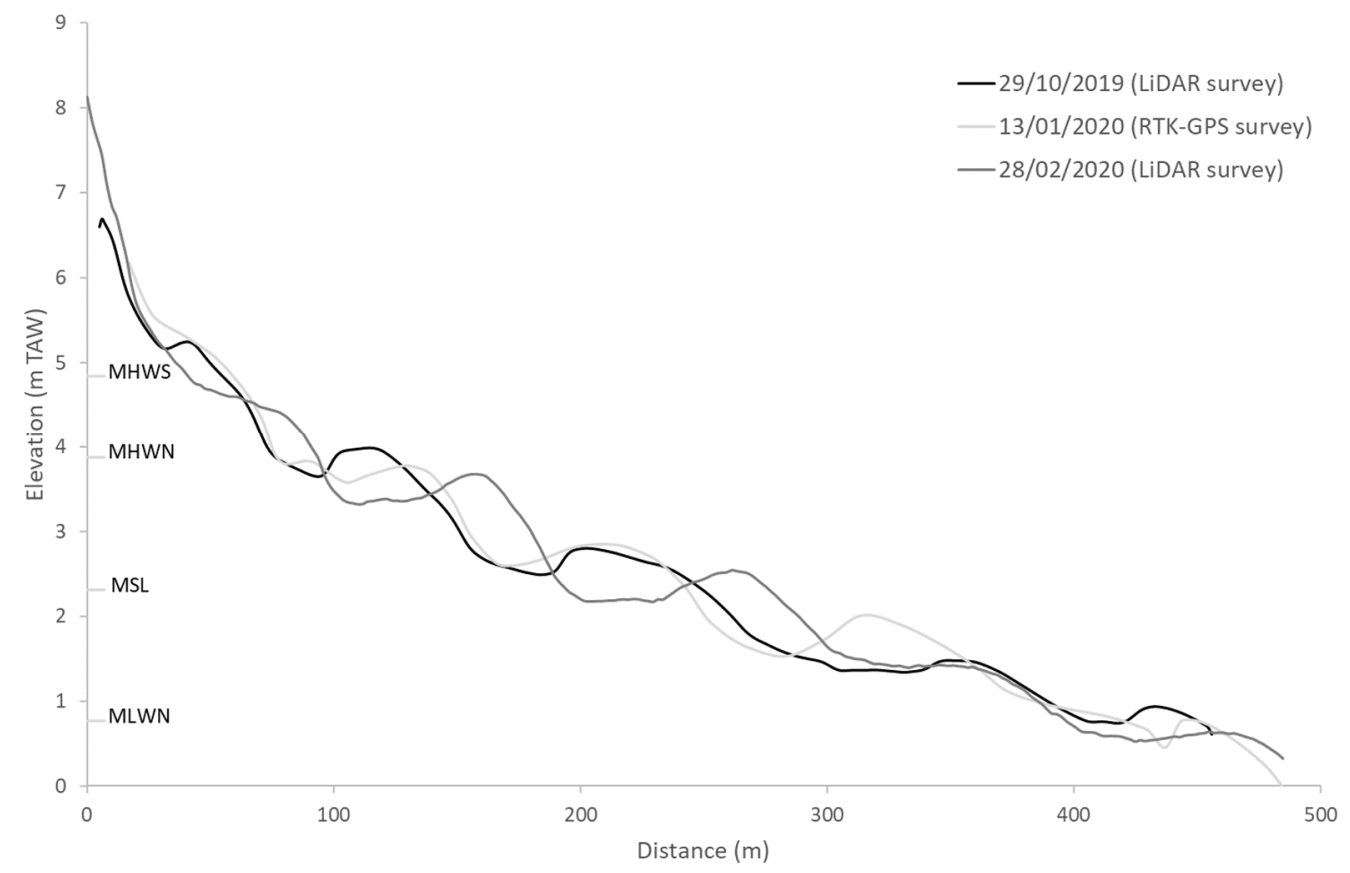

Figure 8. Cross-shore profiles starting from the upper-beach of the pre- and immediately after storm. 


\subsection{Suitability and Applicability of Toolbox}

High-resolution 3D topographic data surveys of multibarred beaches have increased over the last years which allow the thorough investigation of bar morphodynamics. With the PROTECT toolbox, we aimed to implement an automatic bar extraction algorithm in a way flexible enough to be applied to any 3D topographic dataset such as DSMs. Additionally, the bar maps and parameters derived from the PROTECT toolbox (Figure 5) display enough information to investigate storm impact and recovery assessments over a range of intervals from weeks, months to seasons. The validation based on topographic LiDAR dataset demonstrated that the PROTECT toolbox is capable to extract the position of intertidal crest bars accurately (Figure 4). The uncertainty in the elevation characteristics of the bars induces an error in the elevation dimension of $0.10 \mathrm{~m}$ (root-mean-square error) which is about 10 times lower than the bar topography. Topographic LiDAR cannot penetrate the water due to the light absorption. This leads to the absence of data in the deepest parts of the troughs and drainage channels where water could be still present at low tide. Nevertheless, it only concerns a small proportion of the beach surface where the accuracy of the toolbox for detecting the dimensions of these features and volume changes could be limited due to the lack of measurements from the LiDAR sensor. In general, the PROTECT toolbox can be applied to an array of spatially and temporally varying datasets to assess intertidal bar morphodynamics from the short- (storm scale) to the long-term (years).

The PROTECT toolbox can systematically be applied to explore bar morphodynamics anywhere at a broad range of temporal scales. Application of the toolbox requires a temporally dense dataset with a good coverage of the beach including the spring low tide area to ensure a complete coverage of the intertidal zone. Even though LiDAR data surveys are expensive and sometimes collected sporadically, they provide a detailed snapshot of the multibarred beach at the specific time of the acquisition over a large spatial coverage. However, bar dynamics are strongly influenced by a combination of processes interacting on the beach over short- to long term time scales [1]. The comparison of irregular and limited numbers of LiDAR datasets only reveals the cumulative results of processes taking place on the beach, which makes it challenging to evaluate the true bar behaviour and evolution [12]. In our study, the interpretation of the bar migration in alongshore and cross-shore direction is incomplete due to the temporal scale at which the LiDAR surveys were acquired, in disproportion to the scale of a few days at which the storm impact takes place. To understand fully the morphodynamics of the multiple bar system, a topographic snapshot should be provided within a sufficiently long period (> 6 months) and more frequently on a regular interval [10]. The advance of high-resolution 3D survey methods such as unmanned aerial vehicles and terrestrial laser scanners allows repeated surveys at high temporal resolution and at relatively low cost to quantify bar morphodynamics. Applying the PROTECT toolbox by integrating frequent low-cost 3D topographic survey data with LiDAR datasets would permit the increase of the temporal mapping resolution. Similar assessments of post-storm recovery instances at multiple worldwide locations can be used to develop predictive models of multibarred beaches which will support decisionmaking in relation to future storm response and the progressively accelerating of sea level rise, assess vulnerability and to aid guide coastal management efforts.

\section{Conclusions}

This study investigated the severe event Ciara storm, and applied the newly developed PROTECT toolbox to evaluate multibarred beach storm response and post-storm recovery. An exceptional high-resolution LiDAR digital surface models of pre, immediately and after storm of Ciara event on 8-12 February 2020 were collected at Groenendijk beach. This research demonstrates that the PROTECT toolbox is capable to detect the position and elevation of intertidal bars accurately with an error 10 times lower than the observed bar dimension. In addition, the comparison of the detected bars pre- and post-storm surveys indicates that most of the features are concentrated in the middle of the intertidal zone 
from the MHWN to MLWN line. Five bars across the intertidal beach were identified before and 9 months after the storm, contrasting with four bars only observed immediately and 2 months after the event. Another common pattern after the storm is that the bars occupied a number of preferential elevational positions across the intertidal beach. Typically, the inner bar was just below the MHWN, middle bar around the MSL line, and the inner bar around $1.6 \mathrm{~m}$ TAW. However, the bars were different before the storm located in average $0.3 \mathrm{~m}$ higher than the preferential post-storm bar positions and they had a spreader clustering configuration. Furthermore, the severe storm resulted in an overall erosion of the upper-beach equivalent to a decrease of elevation of $-0.14 \mathrm{~m}$. This was followed by a continuous and full recovery after 9 months under fair weather conditions. In contrast, sand budget in the intertidal zone remained stable over the entire monitoring period although the bars showed significant morphological changes. Applying PROTECT toolbox with high-resolution 3D topographic datasets acquired at frequent and broader time scale enables the possibility to increase the mapping temporal resolution from short (storm event) to long-term (years). This will provide useful information for evaluation of the morphodynamics of intertidal bars and their influence on sand volume in beach system. These assessments combined post-storm recovery stages at multiple locations worldwide can be used to develop predictive models of multibarred beach and contribute to the forecast of future storm response.

Author Contributions: Conceptualization, A.-L.M. and M.C.; formal analysis, A.-L.M. and R.M.; funding acquisition, M.C., A.-L.M., R.M., R.H. and P.B.; methodology, A.-L.M. and R.M.; visualization, A.-L.M. and R.M.; writing—original draft, A.-L.M.; writing—review and editing, A.-L.M., R.M., R.H., P.B. and M.C. All authors have read and agreed to the published version of the manuscript.

Funding: This research was funded by the Belgian Science Policy Office, STEREOIII project SR/03/204.

Institutional Review Board Statement: Not applicable.

Data Availability Statement: Topographic data that support the findings of this study are available from the author upon reasonable request. A publicly available forcing factors dataset was analysed in this study. This data can be found here: https://meetnetvlaamsebanken.be/ (accessed on 20 November 2021).

Acknowledgments: The authors thank the Belgian Science Policy Office for providing funding under STEREOIII project SR/03/204. We would also like to thank the Coastal Division of the Flemish Authority for providing the LiDAR survey data.

Conflicts of Interest: The authors declare no conflict of interest.

\section{References}

1. Biausque, M.; Grottoli, E.; Jackson, D.W.T.; Cooper, J.A.G. Multiple intertidal bars on beaches: A review. Earth Sci. Rev. 2020, 210, 103358. [CrossRef]

2. Masselink, G.; Anthony, E.J. Location and height of intertidal bars on macrotidal ridge and runnel beaches. Earth Surf. Process. Landf. 2001, 26, 759-774. [CrossRef]

3. Anthony, E.J.; Levoy, F.; Monfort, D.; Degryse-Kulkarni, C. Short-term intertidal bar mobility on a ridge-and-runnel beach, Merlimont, northern France. Earth Surf. Process. Landf. 2005, 30, 81-93. [CrossRef]

4. Houwelingen, S.; Masselink, G.; Bullard, J. Characteristics and dynamics of multiple intertidal bars, North Lincolnshire, England. Earth Surf. Process. Landf. 2006, 31, 428-443. [CrossRef]

5. Montreuil, A.-L.; Moelans, R.; Houthuys, R.; Bogaert, P.; Chen, M. Characterization of intertidal bar morphodynamics using a bi-annual LiDAR dataset. Remote Sens. 2020, 12, 3841. [CrossRef]

6. Masselink, G.; Kroon, A.; Davidson-Arnott, R.G.D. Morphodynamics of intertidal bars in wave-dominated coastal settings a review. Geomorphology 2006, 73, 33-49. [CrossRef]

7. Miles, A.; Ilic, S.; Whyatt, D.; James, M.R. Characterizing beach intertidal bar systems using multi-annual LiDAR data. Earth Surf. Process. Landf. 2019, 44, 1572-1583. [CrossRef]

8. Andersen, M.S.; Gergely, Á.; Al-Hamdani, Z.; Steinbacher, F.; Larsen, L.R.; Ernstsen, V.B. Processing and performance of topobathymetric lidar data for geomorphometric and morphological classification in a high-energy tidal environment. Hydrol. Earth Syst. Sci. 2017, 21, 43. [CrossRef] 
9. Deronde, B.; Houthuys, R.; Henriet, J.-P.; Van Lancker, V. Monitoring of the sediment dynamics along a sandy shoreline by means of airborne hyperspectral remote sensing and LIDAR: A case study in Belgium. Earth Surf. Process. Landf. 2008, 33, 280-294. [CrossRef]

10. Theuerkauf, E.J.; Rodriguez, A.B. Impacts of transect location and variations in along-beach morphology on measuring volume change. J. Coast. Res. 2012, 28, 707-718.

11. Houthuys, R.; Verwaest, T.; Dan, S. Morfologische Evolutie van de Vlaamse Kust tot 2019: Evolutie van de Vlaamse Kust tot 2019; Versie 2.0; WL Rapporten, 18_142_1; Waterbouwkundig Laboratorium: Antwerpen, Belgium, 2021.

12. Brand, E. Intertidal Beach Morphodynamics of a Macro-Tidal Sandy Coast (Belgium). Ph.D. Thesis, Vrije Universiteit Brussel, Brussel, Belgium, 2019.

13. Haerens, P.; Bolle, A.; Trouw, K.; Houthuys, R. Definition of storm thresholds for significant morphological change of the sandy beaches along the Belgian coastline. Geomorphology 2012, 143, 104-117. [CrossRef]

14. Moelans, R.; Montreuil, A.-L.; Chen, M. Open-source Raster Processing Toolbox for the Investigation of Coastal Intertidal Bar Displacement (PROTECT) (1.1). Zenodo 2021. [CrossRef]

15. Montreuil, A.-L.; Chen, M.; Brand, E.; Verwaest, T.; Houthuys, R. Post-storm recovery assessment of urbanized versus natural sandy macro-tidal beaches and their geomorphic variability. Geomorphology 2020, 356, 107096. [CrossRef]

16. Castelle, B.; Bujan, S.; Ferreira, S.; Dodet, G. Foredune morphological changes and beach recovery from the extreme $2013 / 2014$ winter at a high-energy sandy coast. Mar. Geol. 2017, 385, 41-55. [CrossRef]

17. Roberts, T.M.; Wang, P.; Puleo, J.A. Storm-driven cyclic beach morphodynamics of a mixed sand and gravel beach along the Mid-Atlantic coast. USA. Mar. Geol. 2013, 346, 403-421. [CrossRef]

18. Mulrennan, M.E. Ridge and runnel beach morphodynamics: An example from the central east coast of Ireland. J. Coast. Res. 1992, $8,906-918$ 